\title{
Progreso y precipicio. Recuerdos del futuro del mundo moderno*
}

\section{Jürgen Moltmann, Universidad de Tubinga.}

\section{EI año 2000, ¿un número cero?}

¿Qué es lo que ocurrió propiamente el 1 de enero del año 2000: un viraje de los liempos con la gravedad frente al destino de los alemanes de antaño o un nucvo "milenio" en el feliz progreso del mundo moderno. el "principio del fín del mundo" o tal vez sólo una suntuosa celebración postmoderna de la noche de Silvestre en Berlín, Hamburgo, París y New York?

Según la normal razón humana fue una noche como todos las otras noches anles y después, sin otra especial significación. Y sin embargo, hay un hechizo en este año 2000 con sus tres ceros. ¿Qué clase de hechizo? Tiene que ver con el sistema decimal, con el que venimos midiendo los tiempos desde el comienzo del mundo moderno. Desde el comienzo de la modernidad se impuso la cronología lineal, que desatiende lo que pasa en cada tiempo y sigue acumulando fechas sin descanso. Esta cronología cuadra bien al imparable progreso humano, desde el pasado hacia un futuro siempre mejor. The Past is a prologue of the Future, sc lee en un museo de Washington. Progreso y regresión dominan también nuestros actuales sistemas mundiales. Por eso, en estos giros de los tiempos, nos gusta hacer balance y medir el haber y el deber de los progresos, que hemos hecho. Pero el progreso mismo no se cuestiona, porque, pensamos, avanza presuroso con la cronología año tras año hacia un futuro ilimitado.

¿Pero por qué el año 2000? Según el sistema decimal es claramente admirable todo lo que acaba en cero, porque lo consideramos como un "número redondo", aunque no sea número alguno. Cada diez años un jubileo, cada cien años un centenario, etc... Tanto si hay algo que celebrar, como si no lo hay. ¿Qué es lo que hay en el cero de más atractivo que en el siete o en el doce? Junto con el signo de lo indefinido. el "cero" llegó tardíamente a nuestro sistema numeral

A parecido en /sidorianun, 18 (2000), pp. 289-3/ I 
desde la India, a través de Arabia'. El corte de la respiración o el instante místico, que estalla con la llamada "hora cero", tiene su importancia. ¿Podemos volver a empezar desde el principio con la "existencia en-el-punto-cero", sin pasado y libres de recuerdos? En algunos discursos sobre el cambio de año se dijo: con los tres ceros del año 2000 comienza un nuevo año, una década nueva, un siglo nuevo y tal vez incluso un milenio nuevo. Algo fascinante: cuatro nuevos comienzos. Tenemos la impresión de que se nos abre el futuro más pequeño y lambién el más grande. ¡Qué ilusión tan agradable!

La cosa parece tolalmente distinta, si nos volvemos a lo que pasa en el tiempo, ya que el acontecer efectivo no suele atenerse a nuestro cómputo del tiempo abstracıo. ¿En qué situación nos encontramos hoy tras el siglo XX y tras el siglo XIX?

Estos dos siglos determinarán el futuro del siglo XXI, ninguno de los dos ha pasado y ambos nos sitúan en enormes contradicciones: ahí está el siglo XIX, el tiempo de los fantásticos progresos en todos los ámbitos de la vida, desde la locomotora hasta el avión, desde el telégrafo hasta el teléfono, desde la física clásica hasta la teoría de la relatividad, el tiempo de los descubrimientos y las conquistas; $y$ aquí está el siglo XX: el tiempo de las catástrofes incomparables, Verdún y Stalingrado, Auschwitz y Archipiélago Gulag, Hiroshima y Chernobyl podrían servirnos de nombres para los inconcebibles crímenes contra la humanidad del avanzado y moderno occidente. Ambos siglos siguen hoy presentes: el progreso y el principio. Lo que fue posible una vez no desaparece sin más de la realidad, sino que permanece en ella. Hoy globalizamos el mundo del progreso del siglo XIX y al mismo tiempo tenemos todos los medios listos para la "solución final de la cucstión de la humanidad", mediante unas destrucciones de masas, que ya se desarrollaron y aplicaron en el siglo XX?

En la primera parte de este artículo, hablaré sobre el "nacimiento de la modernidad del espírilu de la esperanza mesiánica", para comprender la época de los comienzos sin fin. En la segunda parte, expondré la época del lín sin coınicnzos, que se inició con la "catástrofe original" de la Primera Guerra Mundial. En la tercera parte, deseo plantear la pregunta por el futuro de la esperanza cristiana y de las esperanzas de la humanidad.

\section{El nacimiento de la modernidad del espíritu de la esperanza mesiánica}

El mundo moderno tiene por lo menos dos comienzos significativos anteriores a la ilustración: el descubrimiento y la conquista de América desde 1492 y la toma del poder cientílico-técnico del hombre sobre la naturaleza.

I. R. Kaplan. Die Geschichse der Null. Francklurt. New York. 2000. En inglés: The Nothing That /s: A Natural History of Zero, London, 1999.

2. Para un análisis parecido $c f r$. Richard Bauckham y Trevor Hart. Hope against Hope Christian Eschaiolog." in Contemporary Content, London. 1999. Cap. I: "The Decline ol Secular Hope", pp. I-26. 
En 1492 se puso la primera piedra para aquel "nuevo orden mundial", que todavía pervive. Con la conquista de América, Europa se vio desplazada desde una existencia periférica en la política mundial al centro del mundo. En 1492 comenzó la toma del poder de los europeos sobre los continentes y los pueblos. Para Hegel, esta fue la hora del nacimiento del mundo moderno". Antes eran los poderes europeos insignificantes en un cotejo mundial con el imperio olomano, con el imperio mongol de India o con el imperio chino. Españoles y portugueses, luego ingleses, holandeses y franceses lueron "descubriendo" América, cada uno para sí. Ahora bien, ¿qué significa aquí y ahora esto de "descubrir"? América no fue descubierta, ni conocida, sino tomada en posesión y configurada, según la voluntad conquistadora". "América, dice el historiador mexicano Edmundo $\mathrm{O}^{\prime}$ Gorman, es una invénción del pensamiento europeo". La vida propia y las culturas propias de aztecas, mayas e incas no se tuvieron en cuenta hasta el dia de hoy, fueron oprimidas como lo extraño y sacrificadas como víctimas a lo propio". Se dieron nombres españoles a islas, montes y ríos, la mayoría de las veces nombres cristianos. La lenguas de los pueblos indígenas fueron prohibidas. El mito jurídico de "los bienes sin dueño" del "país de nadie" y de "la tierra despoblada" legitimó el latrocinio y la colonización. Con la conquista de América, el cristianismo entró en escena como religión europea para el dominio del mundo.

La toma del poder científico-técnico sobre la naturaleza es la otra piedra angular del nuevo orden mundial. En aquel siglo, que media entre Nicolás Copérnico e Isaac Newton, los nuevos científicos empíricos "desencantaron" la naturaleza y le arrebataron el secreto divino, que hasta entonces venía siendo venerado como "alma del mundo" . Con esto cayó el tabú del profundo respeto hacia la "madre licrra" y hacia la "gran vida"?. Las ciencias de la naturaleza llevan "la naturaleza con sus hijos" al hombre (naturalmente al varón), para hacerlo "señor y propietario de la naluraleza", como en aquel tiempo interpretaron este proceso Francis Bacon y René Descartes: mediante la ciencia de la naturaleza y la técnica se resta-

3. G. W. F. Hegel, Die Vernunft in der Geschichte (PhB 171a). Hamburg, 1995. p. 200: "América es según esto el país del futuro. en el que en los tiempos venideros... se revelará la importancia histórica universal". P. Kennedy describe de modo impresionante el poco peso de las potencias europeas en el panorama mundial de 1942. The Rise and Fall of the Grat Powers, New York, 1987.

4. B. Dielschy. Die Tüchen des enidekens. Ernst Bloch, Kolumbus und die Neue Welt, en Jahb. der Emst-bloch Gesellschaft. 1992-1993. pp. 234-251.

5. E. Dussel, Von der Erfindung Amerikas zar Enideckung des Anderen. Ein Projekt der Iransmodernte, Düsseldorl, 1993. De entre los trabajos anteriores es importantc T. Todorov. Die Eroberung Amerikas. Das Problem des Anderen.

o. Para la representación del alma del mundo véase H. R. Schlelte. Weltseele, Geschichre und Herneneutik, Franckfurt, 1993.

7. C. Merchant, The Death of Nature. Women, Ecology and the Scientific Elolution, San Francisco. 1989 M. Suutala, Zur Geschicht der Naturzersiörung. Frau und Tier in der wissenschaflichen Evolution, Franck Jun. 1999. 
blece "la semejanza divina del hombre", que se había perdido por la superstición y la idolatría y con ello se implanta su "dominio en la tierra" (dominium terrae), que se corresponde con el dominio de Dios en el cielo. También aquí se hicieron y se hacen "descubrimientos", que llevan hasta el día de hoy el nombre del descubridor y que últimamente se patentizan, como en el caso del genetista Graig Venter, que quiere apropiarse del genoma humano con miles de patentes, aunque él no lo ha "inventado" e incluso se potencian en vista de la explotación científica. Porque el descubrimiento científico no sólo suprime nuestra ignorancia, sino que además nos convierte en sujetos de los objetos conocidos. Desde entonces, la razón se convirtió en la "razón insırumental" (Max Horkheimer), es decir, la razón guiada por el interés del poder y de la utilidad. Esta eliminó la antigua concepción de la razón como la frónesis, que vincula la ciencia con la sabidurfa. Según la racionalización de la razón científica, que hace Kant, la razón sólo "ve" lo que ella misma hace aflorar, conforme a su propio proyecto, forzando a la naluraleza a que responda a sus preguntas" (prólogo a la Crítica de la razón pura, 2a ed.). "Saber cs poder" y el saber de las ciencias naturales es poder, primero sobre la naturaleza, luego sobre la vida y hoy sobre el futuro. De la ciencia natural y de la técnica, Europa sacó aquel saber disponedor. Para desencadenar la expansión mundial de su civilización con los recursos de los pueblos colonizados. Con la creciente globalización, el mundo cristiano pasó a ser el mundo occidental y a la vez el mundo occidental pasó a ser el mundo moderno, cuyos orígenes históricos dejaron de ser visibles, porque aparece el mismo en Tokio, Singapur, Chicago y ahora también en Franckfort, en Berlín y en todas partes.

¿Qué esperanzas motivaron el descubrimiento europeo del mundo? Fue la visión del "nuevo orden mundial".

Colón buscaba sin duda tanto el jardín divino del Edén como El Dorado, la ciudad del oro". "Dios y el oro" fueron pues los impulsos más fuertes de la conquista". El oro no solamente debería servir para el enriquecimiento personal, sino launbién (como leemos en su diario) para la reconquista de Jerusalén. Porque según la profecía de Joaquín de Fiore, "de España vendrá el que devuelva el arca a Sión”. ¿Por qué precisamente Jerusalén? Porque la ciudad santa debe ser la capital del reino milenario de Cristo, con el que culminará la historia universal. ¿Y por qué los españoles? Porque según la teología política de los teólogos estatales españoles, de los llamados quintomonarquianos, la monarquía cristiana es nada menos que "la quinta monarquía", que según Daniel 7 tomará el relevo de las cuatro monarquías bestiales del mundo, la última, la romana'". Aquella es el reino del Hijo

8. E. Bloch, Das Prinzip Hoffnung, Franckfur, 1959, pp. 853ss. El Dorado und Eden.

9. G. Gutiêrrez. Goll und Gold, Freiburg, 1990.

10. M. Delgado, Die Metamorphosen des Messianismus in des iberischen Kulturen, Eine religionsgeschichliche Sludie. Neue Zeitschrift für Missionswissenschaften. Iınınersee/Scweiz. 1994. pp. 39-50. Si Carlos V dijo que "en su imperio no se ponía 
del Hombre, en el que los santos del Altísimo dominarán el mundo y juzgarán los pueblos. Con la "piedra de Daniel" (Dn 2) y con el "fuego de arriba" (Dn 7) se destruirán todos los demás imperios mundiales, hasta que finalmente llegue la humanidad a ser "un sólo rebaño bajo un sólo pastor". Según el "mesianismo en las culturas ibéricas", esta monarquía cristiana universal durará hasta el final de la historia. Ella representa el "nuevo orden mundial", como decían los españoles antes de la fundación de Estados Unidos. Este es el "nuevo mundo", en sentido mesiánico. Novus ordo saeculorum se dice en el sello de Eslados Unidos. Y en cada billete de un dólar. Esta es la "fe mesiánica de nuestros padres", esto es, el "nuevo orden mundial", que cada presidente de Estados Unidos. confirma en su discurso inaugural". Estados Unidos ha decidido las dos guerras mundiales y, tras la caída del imperio soviético, han quedado como la única superpotencia existente. Por eso, Henry Luce tuvo cierta razón en llamar al siglo XX "el siglo americano". De momento, no parece que el siglo XXI vaya a ser distinto.

¿Qué esperanzas molivaron la civilización moderna en el "mundo viejo"? Fue y sigue siendo la visión de la "edad moderna".

El marco interpretativo dinámico y orientador para la elevación de Europa al dominio del mundo se reconoce por dos símbolos de la esperanza en el futuro: cl Je la espera de una culminación de la historia en el "reino milenario", en el que Cristo reinará con los suyos y juzgará a los pueblos y en la espera de una culminación de la historia, en el "tercer reino del Espíritu", que, según la profecía de Joaquin de Fiore, revelará el reino del Padre y el del Hijo y los completará. Se llama a ambas esperas de la historia "quiliásticas" o "milenaristas"; a su motivación del presente "mesiánica"'?2. Es común a ambas que alli donde influyen, el pasado deja de dominar sobre el presente, como en las sociedades tradicionales; al contrario, es el luturo el que alcanza la prioridad, en la experiencia del tiempo. Con esio ha nacido la "sociedad moderna". Ambas esperas tienen además de común que ven la consumación de la historia en un futuro histórico, no en una caltástrofe que rompa la historia. Con esto, el pasado se convierte en el "prólogo del luluro" y los liempos se dejan dividir en fases o pasos hacia su consumación. "Scmejante a una brújula, que nos brinda oricntación en el espacio y nos capacita para conquistarlo, la brújula escatológica nos orienta en el tiempo, scñalando hacia el reino de Dios, como hacia la finalidad y la terminación última"13.

cl sol", no cxpresaba una constatación, sino la aspiración de la monarqufa cristiana universal: un Dios en cl ciclo, un emperador en la tierra, un imperio dominador de locda la lierra.

11. Cfr. para esto E. L. Tuveson, Redeemer Nasion. The Idea of America's Role, Chicago. 1968 .

12. Ver csto con más Jelalle en J. Moltmann. Das Kommen Gottes, christliche Eschatologie, Gülersloh. 1995. Cap, 3. "Geschichtliche Eschatologie".

13. K. Löwith. Weligeschichte und Heilsgeschehen. Die theologischen Voraussetzungen der. Geschichtsphilosophie. Stuttgart. 1953. p. 26. Löwith quería demostrar que la fe 
Desde el siglo XVII se sucedieron en Europa olas de esperanzas milenaristas, mesiánicas y apocalípticas ${ }^{14}$. Las encontramos en el mesianismo judío del Sabbatai zwi, en el apocalipsis puritano de Oliver Cromwell, en la "teología prolética" de los holandeses y en la "espera de tiempos futuros mejores", en el incipiente pietismo alemán con Amos Comenius, Philip Jakob Spener y en los würtemburgueses Johan Albrecht Bengel y Friedrich Etinger. Todos ellos mezclaron la esperanza en la cercanía del naciente milenio de Cristo con la antigua cspera de la "edad de oro", que según Virgilio debe sustituir a la "edad de hierro". Tales esperas finales han tenido siempre lugar en el cristianismo. Pero con el comienzo de la modernidad, en el siglo XVII, surge la nueva fecha: ahora ha llegado el liempo del cumplimiento, hoy puede realizarse esta esperanza. Después de la "antigüedad" y de la "edad media", comienza ahora la edad moderna; éste es el liempo de la consumación. Ahora culmina la historia universal. Ahora ya es perfecta la humanidad. Ahora empieza el proceso sin freno en todos los ámbitos de la vida, ya no habrá más rupturas cualitativas.

La lamosa triple acta de Lessing "sobre la educación del género humano" de 1777 se convirtió en el escrito fundacional de la ilustración alemana. Llega el tiempo en que cada hombre conoce la verdad por sí mismo, sin la mediación de la Iglcsia, y hace el bien porque es bueno, no por temor al castigo. Este tiempo nuevo comienza "ahora", con el paso de los hombres de la fe eclesiástica histórica a la "fe universal de la razón".

La revelación histórica de Dios se convierte en promesa de lo que ahora pueden conocer los hombres por sí mismos. La oculta "providencia" de Dios se

moderna en el progreso expresa una secularización de la escatología cristiana. Pero no se da cuenta de que se trata en ese caso sólo de la secularización del milenarismo cristiano, pero no de toda la escatología cristiana. Sólo si se espera una "consumación" de la historia universal, puede hablarse de sus "procesos". Lowith no ha tenido en cuenta la apocalíptica cristiana, en la que debemos ver el reverso del milenarismo cristiano. Por eso, su Jibro no se llama: Historia universal y acontecer de la desgracia, aunque esta asociación hubiera sido más plausible después de 1945.

14. Véase J. Taubes, Abendländische Eschatologie (1947), München, 1991. Puesto que sólo trabaja sobre fuentes alemanas, indico también R. Bauckham, Tudor Apocalypse, Sixteenth Century Apocalypticism, Millenarism and the English Reformation: from John Bale to John Foxe and Thomas Brightman, Oxford, 1975. Majore Reeves, Jouchim of Fiore and the Propheric. Future, London, 1976, muestra cuán fuertementc también el protestantismo inglés y la ilustración inglesa sufrieron la influencia del espíritu mesiánico de Joaquín de Fiore. De considerable influencia fue también el libro del gran rabino de Amsterdam Manasseh ben Israel, Spes /sraelis, 1650, dedicado a Oliver Cromwell y que tanto influyó en la readmisión de los judíos en las Islas Británicas. Para eso, Avihu Zakai, Exile and Kingdom. Hisıory and the Apocalypse in the Puritan Migration 10 América, Cambridge, 1992; del mismo autor, From Judgment to Salvation. The Image of the Jews in the English Renaissance, in Wt 59 (1997), pp. 213-230. 
convierte en un palente y pedagógico plan de educación para la humanidad, que asciende y va avanzando hacia adelante"s.

Taınbién en Immanuel Kant encontramos este pathos quiliástico del paso de la humanidad hacia el liempo moderno de la pura te racional'to.

La revolución lrancesa, para el cristiano piadoso un signo apocalíptico del Anticristo, para Kant fue una "señal histórica" de la evolución de la humanidad hacia un estado mejor. Lo que antes se llamaba "reino de Dios", se convirtió para Kant en símbolo del lin ético, al que el hombre debe acercarse ilimiladamente. Aquí encaja también su visión de la "unión ciudadana perlecta en el género humano". en una federación de pueblos que garantizaría la "paz cterna", porque la paz es la promesa de los derechos humanos.

Si se tiene en cuenta este mesianismo de la edad moderna en Europa. entonces. no extraña que para Kant la cuestión religiosa no es: ¿qué es lo que nos vincula con el origen en el pasado? O ¿qué es lo que nos detiene en la cternidad", sino ¿qué tengo derecho a esperar" Sólo un futuro, al que se tiene "derecho a esperar" puede dar sentido a la vida en el tiempo histórico, en las acciones y en los sulirimientos históricos: "¡Si el lín acaba hien. todo está hien!". El futuro. en este sentido patético, religiosamente marcado. se convirtió para el mundo moderno en el nuevo paradigma de la transcendencia.

El siglo XIX, que según unas nolables cesuras comenzó en Europa en 1789 y acabó en 1914, lue en realidad un tiempo de los comienzos, de las utopías y de las revoluciones. Lo que antes sólo pudo esperarse, debcría "realizarse" ahora. Por primera vez se vio la alternativa al mal estado existente del mundo no en el más allá, sino en el aquende futuro, no en otro mundo irreal, sino en los cambios reales de este inundo.

De la revolución francesa surgió la visión democrática de la soberanía popular sobre la hase de los derechos del hombre y del ciudadano; y la gran promesa: "libertad, igualdad, fraternidad" (la "sororidad" debería añadirse más tarde).

De Inglaterra vino la revolución industrial, hermana de la revolución democrática ${ }^{17}$. con la promesa de un bienestar universal para el mayor número posible de hombies. La revolución socialista debería completar la revolución democrática, mediante la "sociedad sin clases", en el "reino de la libertad", que se construye sobre "el reino de la necesidad" de la industria.

15. K. Aner. Die Theologie der Lessingszeit. Halle. 1929; W. Philipp, Das Werden der Aufklärung in theologiegesshichtliche Sicht. Göttingen. 1957.

16. I. Kant, Das Ende der Dinge (1794). Ob das menschliche Geschlecht im Beständigen Fortschreisen zum Besseren sei? (1798) En Ideen zur eine Allgemeinen Geschichte in weltbürgerlichen Absicht (1784) escribe: "Por lo visto la filosoffa puede tener también su quiliasmo" (Achter Salz).

17. Esta tesis la ha sostenido ya Joachim Ritter en vista a Hegel: Hegel und die Französsische Revolution. Köln-Opladen. 1957. 
La conciencia de progreso, avivada por continuos descubrimientos cientifi$\cos$ e invenciones técnicas, confió en un comienzo sin fin. Grandes teorías de la historia, como la de Augusto Comte, Hegel y Marx pusieron los progresos históricos bajo la luz de la consumación del mundo. Simultáneamente, las grandes potencias europeas se dividieron el resto del mundo, en sus imperios coloniales. Sin duda. con la mala intención de dominar el mundo, pero también con el buen propósito de servir a la educación y desarrollo de la humanidad atrasada y subdesarollada.

A través de todo el siglo XIX, las capas culturales de Europa acariciaron el sueño del posible perfeccionamiento moral de los hombres. También este optimismo moral tenía un anliguo presupuesto milenarista. Según el Apocalipsis 20, $2-4$, en el reinado milenario de Cristo será "encadenado Satanás por mil años", de inodo que el bien se podrá expandir sin obstáculos. En el año 1900 pareció cumplirse el sueño del gran dominio europeo con palpable inmediatez: tras la rchelión de los boxers, las grandes potencias europeas se lanzaron a repartirse China, el último país todavía independiente. Todas las misiones cristianas cayeron sobre el supuestamente atrasado pueblo de los chinos con la esperanza final de "cvangelización del mundo en esta generación" (John Mott).

Las características de esta época fueron progreso y evolución, crecimiento y expansión, utopias y revoluciones de la esperanza.

\section{La época de las catóstrofes}

Uno de los símbolos más dinámicos para señalar el vuelco desde el progreso más csperanzador hacia las más espantosas catástrofes del mundo moderno proviene de Walter Benjamin. Se trata de su ángel de la historia:

Hay un cuadro de Klee, llamado Angelus novus. Un ángel representadode tal forma, que parece como si pensara alejarse de algo, en lo que tiene clavada la vista. Sus ojos están bruscamente abiertos, abierta está también su boca y sus alas están extendidas. Así es como debe parecer el ángel de la hisloria. Tiene su rostro vuelto hacia el pasado. Allí donde se nos muestra una cadena de episodios, él ve una única catástrofe, que amontona sin cesar escombros sobre escombros y se los va arrojando al ángel a sus pies. Este desearía quedarse, despertar a los muertos y recomponer los desirozos. Pero sopla desde el paraíso un huracán, que le embiste tan fuertemente sobre sus alas, que ya no puede cerrarlas. Este huracán lo empuja irresistible hacia el futuro, al que él vuelve la espalda, mientras que el montón de cascotes crece hacia el cielo. Eso, que llarnamos progreso, es el huracán ${ }^{18}$.

18. W. Benjamín, Illuminationen. Ausgewählie Schrifien, Franckfurt, 1961, pp. 272273. Para esto. Gershom Scholem, Walter Benjamin und sein Engel, Franckfurt, 1983; Sı Mosés; Der Engel des Geschichte. Fr. Rosenzweig, W. Benjamin, Greshom Scholem, Franckfur. 1994. 
¿Dónde encontramos esos "cscombros sobre escombros", que ha dejado tras de sí nuestro progreso histórico? Queremos traer a la conciencia las huellas de unos torturantes recuerdos.

La bella cara superior mesiánica de la historia europea tiene también su fea cara inlerior apocalíptica: el progreso victorioso de los pueblos europeos en cl siglo XIX ha llevado al retroceso ruinoso de los otros pueblos. El mundo moderno es sólo en un tercio el primer mundo moderno, en dos tercios es el tercer mundo moderno. La edad moderna los ha producido a ambos, al mundo moderno y al mundo submoderno, como me guslaría llamarlos. Para los pueblos oprimidos del tcrcer mundo, por largo tiempo esclavizados y en todo caso explotaJos, el mesianismo de la edad moderna europea jamás fue otra cosa que el apocalipsis de su destrucción. Primero, la reducción a la esclavitud de los africanos de 1495 a 1888 hizo posible la economía latifundista en América. Azúcar, algodón, café y labaco cuentan como "cosechas de esclavos". Al principio también el oro y la plata de América Latina crearon los capitales, con los cuales se consıruyó la sociedad industrial de Europaly . Desde el "Iriángulo comercial" Iransallántico (esclavos de Africa y América, materias primas y metales preciosos de América a Europa, mercancías y armas de Europa a Alrica) creció la riqueza de los países europeos. Pero este comercio destruyó, mediante el tráfico de hombres, los reinos y las culturas africanos y, mediante una economía de exportación, destruyó la economía de subsistencia de América y sacrificó aquellos pueblos al desarrollo europeo.

No fue muy distinta la suerte que corrió la naturaleza de la Tierra. El coinienzo de la moderna sociedad industrial fue también el principio del " Fin de la naturaleza" "II. La dilusión de la civilización cientílico-técnica, tal como la conocemos hasta ahora, ha llevado a la destrucción creciente de especies de plantas y animales. Por la emisión de gases de la industria surge aquel "efecto invernadero", que alterará en los años próximos el clima de la tierra con consecuencias graves. Se desmontan hosques lluviosos. Se sobreexplotan los prados, crecen los desiertos. La población mundial se ha cuadruplicado en los últimos sesenta años ( $m$ is años de vida) y seguirá creciendo. La necesidad de medios de vida y la eliminación de basuras crecerán proporcionalmente. El ecosistema del planeta azul se desequilibra. No se trata sólo de una crisis del medio ambiente, sino lambién de una crisis del mundo industrial mismo. La destrucción de la naturaleza, que estamos viendo todos los días, enraíza en una relación perturbada del hombre moderno con la naturaleza: no es posible erigirse en señor y propietario

19. Para esto es siempre fundamental E. Galeano, Die offenen Adern Lateinamerikas. Die Geschichte des Kontinents von der Enideckung bis zur Gegenwart, citado según la nueva edición. Wupperal, 1981. Para la historia de la esclavitud: D. P. Mannix y M. J. Cowley, Black Cargoes. A History of the Aslantic Slave Trade, New York, 1962.

20. W. Leiss. The Domination of Nature. New York, 1972: McKibben. The End of Nature. New York 1989. 
de la naturaleza y a la vez ser uno mismo sólo "una parte" de la naturaleza y depender de ella. La moderna cultura del dominio ha producido su propia dimensión inferior, que, haciendo desaparecer los espacios naturales de la vida, presagia li calástrofe de ésla. Aquí se reconocen con claridad los "escombros sobre los escombros" de Benjamin. Si miranos la evolución de los últimos productos de la industria en la EXPO 2000). Ienemos una sensación de progreso, pero si miramos los crecientes montones de hasura en la tierta, el mar y el aire, entonces, nos asallan angustias de catástrole. ¿Justifica nuestro progreso este sacrilicio?

Fin la primera guerra inundial de 1914-1918, se desiruyeron mutuamente las grandes potencias curopeas cristianas. Fue una guerra de exterminio sin objetivos de guerra claros en ninguna de las dos partes. Un símbolo de esto lue la halialla de Verdún, en 1916"'. Según el plan alemán, debería haber sido una "batalla de desgaste". La intención destructiva, no la esperanza de la victoria, dominó la estrategia militar. Tras seis meses de batalla, había ya 600,000 muertos y apenas se habría ganado o perdido terreno. Los alemanes comenzaron la guerra de gas y no ganaron nada. El entusiasmo patriólico ante la guerra en $1914 \mathrm{se}$ convirtió en nuda hestialidad del puro nihilismo. En Europa sc apagaban las luces. The lamps a'e going out all over Europa, dijo el ministro de exteriores inglés Edward Greyk, en 1914: we shall nor see then lit again in our lifetime. Con eso, las luces de la ilustración y del glorioso progreso se fucron también a un mundo mejor. Era como si el progreso se hubiera vuelto contra sí mismo y devorara a sus propios hijos. Lo que hemos sulirido y sulrimos en el siglo veinte es un apocalipsis sin esperanza. destrucción sin justificación, puro placer en el tormento, violación y ascsinato. El impulso de autodestrucción aceleró en Europa la "decadencia de occidenie". La ćpoca, que comenzó en 1914 y cuyo lin desconocemos (tal vez acabó en 1989) se convirtió en la age of axiet) (D. D. Auden).

La segunda Guerra Mundial de 1939-1945 prolongó la obra destructiva nihilista del mundo moderno. Bajo el camullaje de los abusivos símbolos de esperanzá del "icrcer Reich" o del "Reich milenario" se impulsó en Alemania la "solución linal" de la cucstión judía, en Auschwitz, y lueron aniquilados "los pueblos del cste", mediante el trabajo y el hambre. Se liquidó, linalmente, la autodestrucción de Alemania, en 1945, con unas declaraciones cínicas de su "Führer". Empezaron entonces los exilios forzados de pucblos, que supusieron millones de víctimas. En agosto de 1945, se castigó a Japón con dos bombas atómicas, que Inataron in situ a cientos de miles de seres humanos. En el culto fascista al dictador se celebraron la nuda violencia, es decir, la que no necesita legitimación alguna, y cl desconsiderado "poder de imponerse". En la Unión Soviética, Stalin aniquiló

21. G. Werth. Verdun. Die Schlacht und der Mythos. Bergisch-Gladbach, 1982, p. 53, sobre la dirección y la planificación del ejército alemán: "la intención destructora dominó al criterio militar en el paso de un siglo a olro". En Verdún no interesaba vencer. como en Sedán en 1870, sino "aniquilar". 
clases y poblaciones enteras, primero por hambre, luego por trabajo y enfermedad. en su "Archipiélago Gulag". Mao Tsetung heredó ese terrorismo desde arriba, de partido y de Estado. Y otros numerosos y menores hombres de poder, como Pol Pot, en Camboya, aprendieron de ellos el asesinato de su propia población. "Limpieza étnica" es la perversa expresión de estos años. La recaída en formas supuestarnente superadas de crueldad personal contra los más débiles en los Balcanes, en Africa y ahora en Indonesia, es algo espantoso. Sería cínico seguir hablando de progresos morales de la humanidad por medio de la civilización. Hitler y Stalin y todos sus dóciles colaboradores nos han convencido de que el poder del "mal radical" no se ha roto. Por eso, tenemos por más realistas las escenas del lín del mundo, las fantasías de destrucción y las películas lipo Apocalypse now que los bellos cuadros csperanzadores del siglo XIX sobre la edad dorada y la paz cicina.

El siglo XX no ha traído al mundo ideas nucvas, visiones o utopías, que pudicran darle un sentido a la historia. Los campos de cadáveres de la historia gue hemos visto, nos prohíben loda donación de sentido y toda teodicea, loda idcología del progreso y todo gusto por la globalización. El progreso ha dcjado Iras de sí escombros y víclinas y ningún luluro hisıórico repara estos dolores. Ningún luturo tnejor pucde garantizarnos que aquellos sulrimientos no lucron "cn vano". Una total incapacidad de sentido ante la historia acaecida en el siglo $\mathrm{XX}$ ha sustituido a la conlianza en el luturo del siglo XIX. Si los logros de la ciencia y de la técnica pueden emplearse para cl aniquilaıniento de la humanidad (y si pucden, lo serán algún día), resulta dilícil enlusiasmarse con el internet o la tecnología genética. Toda acumulación de poder acumula también cl ricsgo de su abuso. Pero es esto lo que dehería habernos enscñado el siglo XX, en visión retrospectiva hacia el siglo XIX: es imposible consumar la hisıoria deniro de la historia. No hay futuro histórico que lleve en sí el potencial para eso. Y no es posible consumar la historia, si uno mismo se reduce a un ser hislórico.

\section{Puentes para el futuro}

Llamo a las esperanzass, que apuntan al luturo del próximo milenio, puentes para el futuro, porque deben construirse sobre los precipicios del aniquilamien10. que heinos experimentado en el siglo XX. Son prácticamente las mismas esperanzas que en el siglo XIX llamaron a la vida al mundo moderno (la revolución democrálica y la revolución industrial), pero son esperanzas actuales que, por las malas experiencias, han debido hacerse prudentes. No deben seguir siendo tan confiadas en el progreso y ciegas hacia los peligros, como entonces, cuando vieron la luz del mundo. Hoy deberán ser esperanzas con cautcla y consideración. Expresado objetivamente: esperar y trahajar por el luturo sin arrogancia y sin descsperación. Con las esperanzas masivas del siglo XIX existimos hasta las lumbas masivas del siglo XX. Ya no debemos volver al próximo milenio llenos de csperanzas o ccépticos, necesitamos una reconciliación con el 
pasado del siglo $\mathrm{XX}$, a fin de que este siglo se conviera de verdad en pasado para nosotros y no vuelva a alcanzarnos con sus calástrofes.

\subsection{El futuro de la esperanza cristiana. Resurrección de los muertos: espe- ranza para los que pasaron}

Anles de abordar las conexiones de las esperanzas seculares del siglo XIX en vista del siglo XX, desearía volver otra vez al "ángel de la historia" de Walter Benjamin: ve amontonarse ante sí en el pasado "escombros sobre escombros". el montón de los escombros de la historia crece ante sus ojos ampliamente abiertos hacia el cielo. Esıá inmóvil, porque "el vendaval del paraíso" le ha paralizado las alas, hasta el punto de que no puede cerrarlas. ¿Pero qué es lo que quería hacer propiamente este ángel? ¿Para qué fue enviado? "El querría quedarse, despertar a los muertos y recomponer los destrozos". Pero no puede hacerlo, mientras el huracán le paralice sus alas. "Este huracán es lo que llamamos progreso", dice Benjamin. Dicho al revés: si pudiéramos interrumpir este huracán y prescindir del viento del progreso, entonces, el ángel podría despertar a los muertos y recomponer los detrozos y podríamos acordarnos de todo eso y sanar nuestros recuerdos.

El cuadro bíblico que se encuentra detrás de esto, lo tenemos en Ezequiel 37: la resurrección y la reunificación de Israel. El proleta es llevado en el Espíritu del Señor a un campo amplio, "lleno de huesos de muertos". Esta es la mirada hacia atrás, hacia la historia de los sufrimientos de Israel. Y los huesos "estaban muy secos". Entonces, el profeta oye la voz: "Mira, yo quiero lanzar un soplo (Ruah, fuerza vilal) sobre ustedes y volverán a vivir y tú debes decirle al soplo: Viento, ven aquí desde los cuatro vientos y sopla sobre cstos muertos, de modo que vuelvan a vivir. Luego que experimentó esta visión de la resurrección de los muertos, se vuelve el proleta a su pueblo y le anuncia: Ahora dicen: nuesiros huesos están calcinados. nuestra esperanza se ha desvanecido. Estamos acabados... Pero el Señor dice: infundiré mi espíritu en usledes, para que revivan, les eslableceré cn su tierra (Ez 37, 11. 14).

"Despertar a los muertos y recomponer los destrozos", ésta es la esperanza del luturo para el pasado. No hay ningún fuluro histórico en el que pudiera pasar esto. Tendría que ser un futuro para toda la historia y encontrar en esto su fundamentación. Porque no son los hombres mortales los que despiertan a los Inuertos, y los que han destrozado no podrán recomponer los destrozos. Ningún luluro humano puede reparar los crímenes del pasado. Pero para poder convivir con este pasado de los escombros y de las víctimas, sin tenerlos que reprimir ni que repetir, necesitamos esta esperanza trascendente de la resurrección de los muertos y de la reconstrucción de lo destruido. Debido a la resurrección del Cristo desırozado, está la esperanza cristiana del futuro. en el núcleo de la esperanza de la resurrección. Sin esperanza para el pasado no hay esperanza para el 
futuro, porque cuanto llega a ser, pasa, lo que nace muere y lo que todavía no es, llegará un momento en el cual no vuelva a se $r^{22}$. La esperanza de la resurrección no se centra en un futuro dentro de la historia, sino en el futuro para la historia, en el cual se disolverán las dimensiones trágicas de la historia y de la naluraleza.

Si el futuro de la historia se determina por la resurrección de los mucrtos, entonces, también nos alcanza en él nuestro propio pasado. Entre los muertos nos salen también al encuentro los encarcelados, los gaseados, los asesinados y los "desaparecidos": los muertos de Verdún, Auschwitz, Sıalingrado e Hiroshima nos esperan.

Sólo el que recuerda, puede mirarle a los ojos a este futuro, que se llama "resurrección de los muertos". Y sólo el que mira hacia este futuro, puede recordar verdaderamente el pasado y vivir en su presente. Una "cultura del recuerdo", por la que hoy preguntan muchos, debe ser sostenida por una "cultura de la esperanza", porque sin esperanza en un futuro del pasado y de los que pasaron, se hunde el recuerdo en nostalgia y, finalmente, en el olvido impotente o se mantienc tan fuertemente el recuerdo, que ya no se le vuelve a ir, porque no puede deshacerse de él. "El recuerdo acelera la redención". cstá escrito en cl Yad Vashem de Jerusalén. "Los muertos están muertos, pero nosotros los despertamos", decía el historiador Leopoldo von Ranke. "Los tratamos directamente. Ellos nos exigen la verdad"'?"

El huracán que llamamos "progreso" sopla en direcciones opuestas, si comparamos a Benjamin con Ezequiel. Para Benjamin sopia Jesde el paraíso, es decir, expulsa a los hombres cada vez más lejos de su patria original. El huracán de la resurrección no sopla desde el pasado hacia el fuluro, sino desde el futuro hacia el pasado y trae consigo lo imposible de recuperar: los muertos y sana lo insanablemente roto: los escombros. Lo barruntamos ya en el Espíritu de pentecostés. que nos vivilica con "las fucrzas del mundo futuro" ( $\mathrm{Hb} \mathrm{6,5).}$

¿Cómo se relacionan mutuamente estos dos huracanes, "progreso" y "resurrección"? ¿Cómo pueden vincularse la esperanza transcendente en Dios y las esperanzas inmanentes de los hombres? Creo que en sentido contrario ${ }^{24}$. Porque y en cuanto la esperanza en la resurrección ve el futuro para los que pasaron, los hombres cobran del presente valor para el futuro. Porque existe la gran csperan-

22. No es posible fundamentar una esperanza permanente sobre una ontología del "todavía-no-ser" (E. Bloch. Philosophische Grundfragen I, Franckfurt, 196I).

23. R. Witıram. Das Ihteresse an der Geschiche. Göttingen, 1958. p. 32.

24.W. Benjamín cn olro lugar, p. 280: "Por eso nada que sea puramente histórico Jche intentar asociar lo mesiánico. Por eso, el reino de Dios no es el relos de la dínamis histórica... Visto históricaınente, no es el lïn. sino el punto final... Lo profano no es una calegoría del reino, pero sí es una categoría. por ciento una de las más auténticas. de su cercanía apenas perceptible". 
za en la superación de la muerte y del tiempo efímero, se fortalecen nuestras pequeñas esperanzas en mejores tiempos del futuro y no caen en brazos de la resignación y del cinismo. En plena época de la angustia, esperamos "a pesar de ıodo" y no nos rendimos. Ganamos valor para el "ser-ahi", a pesar del "no-ser". como acertadamente lo ha formulado Paul Tillich". Nuestras limitadas esperanzas humanas para los venideros se convierten entonces en reacción al futuro divino para los que pasaron.

\subsection{El fuluro de la revolución democrálica}

Agradecemos la democratización de la vida política a la doble revolución americana y francesa. Con las dos comenzó el siglo XIX. Desde 1989 y tras enormes luchas y víctimas, se ha impuesto en el mundo occidental y moderno la democracia liberal contra el dominio de la violencia fascista y contra la dictadura del proletariado comunista. Pero hoy tenemos una polílica democrática en unas condiciones distintas a las del siglo XIX.

Democracia de la ausencia. Actualmente, las modernas democracias no se ven tan amenazadas por unos partidos totalitarios de derecha o izquierda, como por la apatía del pueblo, del que, sin embargo, procede "lodo el poder del Estado" (Constilución alemana 10,2). La abstención electoral es sólo un síntoma de csta apalía. ¿Dónde están sus más profundas raíces"? Pienso que están en que vemos la democracia como un estado que tenemos, pero no como un proceso en el cual estanos comprometidos. La democracia es un inclausurable proceso de deınocratización público, que sc va expandiendo en la historia y que reclama una participación activa, un interés de comunión y un compromiso personal de las ciudadanas y los ciudadanos. Si este proceso de democratización se paraliza, cnlonces, cl interés político del pueblo se vuelve también paralítico. Y el lugar de la necesaria democracia de participación lo ocupa, entonces, una peculiar democracia de la ausencia. Los hombres sc retiran a la vida privada o a sus empresas económicas y no quieren que se les importune más con la política. Pierden todo interés y no vuelven a participar. Así, una "clase de políticos" se aleja como exiraña al pucblo y el pucblo pierde la contianza en los políticos. Surge una partidocracia, como lo lamentaba Richard von Weizsacker: los partidos ya no inlluyen en la "formación de la voluntad popular", como lo exige la Ley Fundamentill alcmana. 21, I, sino que imponen al pucblo su propia voluntad.

La clemocracia como proceso abierto al futuro sólo pernanece viva en cuan10 sc vea motivada y movilizada por la esperanza en la implantación real de los derechos humanos. Los derechos del ciudadano garantizados en las constituciones son justos, si se corresponden con la Declaración Universal de los Derechos Humanos de 1948 y $1966^{\%}$. Lo mismo que obscrvamos en las luchas por los

25. P. Tillich. Der Mul zum Sein (1953), Stultgar. 1958 (3a. ed.).

26. J. M. Lochmann y J. Molimann. Das Recht und Menschenreche. Neukirchen, 1977. 
derechos de las inujeres, los niños, los disminuidos, los asilados y de otros grupos marginados, la transformación democrática de los derechos humanos en dercchos civiles de nuestro ámbito local es algo que permanece abierto. Necesitamos la movilización de un gran número de iniciativas civiles libres y espontáneas, en los planos local y regional, para realizar los derechos humanos. Pienso que la democracia de la participación merece la pena, si tiene como fin la implantación de los dercchos humanos.

Los derechos humanos son universalmente válidos para todos los hombres. Son indivisibles. De aquí se sigue que todo hombre no es sólo un miembro de su pueblo. un ciudadano de su Estado, un adepto de su comunidad religiosa etc..... sino también sujeto de unos "derechos humanos irrenunciables". Los derechos humanos no son en la aclualidad un simple "ideal" de Naciones Unidas, como se dice en el preámbulo, sino algo reclamable jurídicamente, en la medida en que haya tribunales internacionales. Lo que ha ocurrido en los Balcanes ha sido, sin duda. horroroso, pero que los responsables de crímenes contra la humanidad y de violaciones de los derechos humanos se vean denunciados ante el tribunal de La Haya y se vean condenados por éste, constituye un pequeño progreso. Los delitos contra la humanidad y (como espero) los delitos contra el medio ambienic deben ser penados, para que tanto los derechos del hombre, como los derechos de la naturaleza Ileguen a ser derechos fundamentales de una sociedad humana global.

De la amenaza atómica se sigue el deber de la paz, en las regulaciones de los conllictos entre estados. Las armas atómicas y otras armas destructoras de masas no son armas militares, sino políticas.

Para evilar la destrucción nuclear del mundo, siempre posible (aunque a veces no muy probable), se urge aún más al Estado moderno y a la comunidad de los estados asociados a hacer una tarea muy antigua, apocalíptica. El poder que debe decener la destrucción del lin de los tiempos, fue denominado katé ejon. Estc poder "del detener" procede de la profecía del Anticristo en 2Tesalonicenses 2. 7ss.: "Porque el misterio de iniquidad está ya en acción: sólo falta que el que por el imomento lo detiene se quile de en medio". El que de momento lo "detiene" cra el Estado romano, para la cristiandad de Roma; para Carl Schmitt, la antimevolucionaria santa alianza, en el siglo XIX, y en el siglo XX, la dictadura antibolcheyique de Hitler" ${ }^{22}$. Podemos olvidar hoy las angustias ideológicas de todos ćstos, ya que la destrucción de la humanidad y de la tierra habitable es hoy real. Por cso, todo Estado tiene ante sí la tarea urgente de detener la autodestrucción atómica de la humanidad.

27. H. Meter. Die Lehre Carl Schmitts. Vier Kapitel zur Unterscheidung Politischer Theslogie und Politischer Philosophie. Stutgart, 1994, pp. 243-249. 
Vivimos en el "liempo linal", dijo con razón Günther Anders, que no pensaba en ningún apocalipsis, sino en aquel "tiempo" en el que el lin se ha hecho posiblc, en cualquier momento ${ }^{2 x}$. Por eso incumbe al Estado junto con el poder de detener la catástrofe nuclear la tarea positiva de ganar tiempo y alargar los plazos ${ }^{20}$. Con cada año en el cual se pueda detener la destrucción, ganamos tiempo para la vida y para la paz. No tenemos tiempo sin límites. Esto tue una ilusión del siglo $X I X$ con su le en cl progreso. Existimos en un tiempo con plazo señalado y tenemos que ganar tiempo. Una verdadera tarea histórico-mundial del Estado moderno que está bajo la sombra de la destrucción atómica.

\subsection{EI futuro de la revolución industrial}

La revolución industrial ha despertado aquella fe movilizadora en el progreso, que caracterizó al siglo XIX. Hoy no necesitamos ya justificar aquella "fe", ni tenemos que seguir criticándola, ya que por el principio de la competencia se ve cada producción forzada al progreso. Industrias y mercados se ven incluso condenados a un progreso continuamente acelerado. El que no moderniza, ni racionaliza, ya ha perdido. El progreso ha caído en la "Irampa de la aceleración". "Quien cabalga sobre el tigre, ya no se haja de él".".".

Por eso, liene poco sentido criticar el progreso como tal. Pero sí tiene mucho sentido la pregunta por sus objetivos, a fin de corregir su curso, si cslo resulta deseable. El progreso mismo es un medio para un fin, pero no establece los fines humanos. Normalmente medimos el progreso por el crecimiento del poder. del poder económico, financiero, militar y cultural. Pero el poder en sí no es un fin humano, sino sólo la acumulación de medios, con los cuales alcanzar fines humanos. Cada año estamos mejor equipados para alcanzar lo que queremos, pero i.qué es propiamente lo que queremos? La mayor parte de los grandes proyectos técnicos no ha surgido mediante una lormación democrática de la voluntad popular, sino al margen de ésta. No se tomó en Alemania ninguna decisión popular sobre la construcción de instalaciones nucleares. Tampoco tenernos hoy discusiones democráticas sobre los alimentos alterados por la tecnología genética.

Desde el final del conflicio entre el este y el oesle se llama al progreso globalización. Este proceso estaba ya en curso en el siglo XIX y al comienzo del siglo XX. Tras 1989, hemos vuelto a coneclar con el tiempo anterior a 1914. Pero lo mismo que el progreso, la globalización, entendida literalmente, no pasa

28. G. Anders. Die atomare Drohung, cuarta edición ampliada con un prólogo sobre "tiempo final y viraje de los tiempos" (1959), München, 1983.

29. J. B. Melz, Glaube in Geschichte und Gesellschaff, Mainz. 1977, prio. 10: Hoffnumg als Naherwartung oder der Kanjf um die verlorene Zeit, pp. 149-160.

30. W. Stahel, Die Beschleunigungsfalle oder der Triunph der Schildkröle, Stultgart, 1995. 
de ser un concepto cuantitativo: lo que tuvo un valor particular, debe hacerse ahora universal. Lo local debe llegar a ser global. Lo mismo que el progreso, la globalización no es más que un medio para un fín, pero no un fin humano mismo. Mientras sólo se trate de ganar poder, el proceso de globalización carece de toda cualidad. Claramente, se trata ante todo del dominio, de la explotación y de la comercialización de la naturaleza de esta tierra. Cada vez menos, pero cada vez mayores global players se reparten el negocio. Pero sea que los logros a corto plazo vayan o no a llevar a largo plazo a la bancarrota de la humanidad y al colapso del ecosistema terrestre, debemos comenzar el debate público sobre los lines humanos y los propósitos de la globalización.

A fin de evitar la destrucción de la tierra por una explotación desconsiderada. es bueno concentrarse en la conservación de la creación y proteger la vida, mediante convenciones de bioética. También es bueno optar por un "desarrollo sostenido". Pero con esto se cae inevitablemente en una ética conservadora y la ética conservadora siempre llega demasiado tarde. Es mejor oponer un contramodelo a la globalización del poder, que se concentre en los fines e intenciones humanos del mismo.

Tenemos un modelo para determinar los fines humanos de un poder globalizado y con ello corregir el curso de la evolución del mundo moderno. Se oculta en el sencillo concepto de oikoumene, hasta ahora sólo aplicado en el ámbito intraeclesial". En griego, oikoumene es un concepto cualitativo y significa "todo el orbe habitado", como corresponde a su raíz en la palabra oikos, casa. Por la constatación de un mundo habitado por los hombres, podemos formar el concepto teleológico de un mundo habilable y de una humanidad a la cual hay que domiciliar en esta tierra. El gobiemo doméstico de esta tierra debe mantener una habilación bien preparada para la humanidad y, por su parte, los hombres deben querer habitar en este sistema terrestre y no oponerse por más tiempo a la naturaleza de un modo extraño y hostil ${ }^{32}$.

Si el lin del progreso y de la globalización del poder humano no es el dorninio y la posesión de la tierra, sino la habitación en ella, entonces, debemos despedirnos del moderno complejo occidental de dioses, de llegar a ser "señores

31. G. Müller-Fahrenholz, Ekumene-Glücksfall und Ernsıfall des Glaubens, epolDodumentation 28/1998. 3-6.

32. Si esto es así. se echa de menos una antropología ecológica. La antropología moderna de M. Scheler, A. Gehlen, H. Plessner, W. Pennenberg y olros parte de la "apertura al mundo" y de la "autotranscendencia" del hombre, para distinguirlo del animal. Pero esla distinción se remonta a J. G. Herder, Uber den Ursprung der sprache (1770), Bcrlin. 1959. que escribe en la p. 21: "La naturaleza fue para êl la más dura madrastra, mientras que fue la madre más cariñosa para cada insecto". Para la nueva antropología ecológica habrá que tener en cuenta las concepciones de la nueva antropología leminista. 
y propietarios de la naluraleza", como lo prometió René Descartes, en su teoría de la ciencia, al comienzo de la época moderna".

La tierra puede vivir sin el género humano y, de hecho, ha vivido así durante millones de años, pero la humanidad no puede existir sin la tierra, porque de ella procedemos. Por lo tanto, los hombres dependen de la tierra, pero no la tierra de los hombres. De este simple conocimiento se sigue que es la civilización humana la que se debe integrar en el sistema terrestre y no al revés, la naluraleza de la lierra someterse al dominio del hombre ${ }^{\text {is. }}$.

Solamente gente extraña explota la naturaleza, destruye los bosques por la lala, deja vacíos los mares por la pesca y no para de un lado a otro como los nómadas. Pero el que quiere habitar y vivir allí, está interesado en la conservación de las bases de su vida y conservará su medio natural capaz de vida. Intentará compensar cualquier intervención en la naturaleza y establecer el equilibrio. Los conflictos económico-ecológicos son hoy, en su mayor parte, conflictos entre las grandes empresas extranjeras y los habitantes, conflictos, por lo tanto, entre los intereses de la explotación, por una parte, y el interés en la habitabilidad de la naturaleza. por la otra.

Después de la globalización del poder necesitamos, lógicamente, una globalización de la responsabilidad. No podemos continuar con la globalización de la economía, mientras la política sigue limitada por el Estado nacional. La economía necesita unos presupuestos políticos y la polftica aquellos fines humanos, en vista de los cuales se unilique la humanidad.

El potencial de la humanidad, que tiene que seguir desarrollándose científica y técnicamente, no debe emplearse en la lucha destructora por el poder, sino que lodavía puede aplicarse a una habitabilidad sostenida de la lierra por la humanidad. Y entonces, no sólo se "conservará" la creación, como hasta hoy se dijo, en iono tan conservador, sino que se la desarrollará más y más, en dirección a su lin. Porque se la destinó a ser la casa común de lodas las criaturas de la lierra y dehe llegar a ser patria y espacio habitado para todos los seres vivientes.

En última instancia, la tierra debe incluso convertirse en morada de Dios: "como en cl cielo, así en la lierra".

Si el Eterno vicne, para "habitar" en la tierra, entonces, esta tierra se converlirá en "templo" de Dios y el Dios sin descanso de la esperanza y de la historia llegará a su descanso. Esta es la gran visión bíblica, es decir, judía y cristiana de esta tierra. Es la promesa final: "Mira, esta es la morada de Dios con los hombres; él habitará con ellos y ellos serán su pueblo" (Ap 21, 3, según Ez 37, 27).

33. R. Descartes, Abhandlung über die Methode (1637), Mainz, 1948, p. 145.

34. J. Moltmann, Gott im Projekt der modernen Welt. Beitrüge zur üffenslichen Relevanz der Theologie. Gütersloh, 1997, pp. 89-110. 
Lal Shekimá delinitiva, csta encarnación cósmica de Dios, es el futuro divino de la licrra. En la cspera de esto, trataremos la tierra ahora y aquí ya como "templo de Dios" y consideraremos santas sus criaturas. Los hombres no somos "señores y propictarios" de la tierra, sino que tal vez. lleguemos a ser algún día los sacerdotes y las sacerdotisas de la tieita, para representar a Dios ante la lierra y la licra ante Dios, a lin de que veamos y gustemos a Dios en todas las cosas y percihamos todas las cosas en el brillo de su arnor. Esto scría una cosmovisión salcramental, capaz de superar la actual cosmovisión cientílico-ićcnica. 